\title{
Formas atípicas de Hipertermia Maligna Anestésica
}

\section{Atypical forms of anaesthetic malignant hyperthemia}

\section{Maria Anita Spindola}

Programa de Hipertermia Maligna do Hospital Universitário da Universidade Federal de Santa Catarina UFSC.

Mesmo à luz dos conhecimentos atuais não há, segundo Hopkins, 'uma apresentação clínica que seja específica para HM”. Um grande desafio da HM é a sua expressividade variável. Não está esclarecida a razão da variabilidade clínica que determina a gravidade de uma crise de HM. Um fator a ser destacado é a heterogeneidade genética, de locus e alelos. Os fatores epigenéticos na modulação da resposta clínica também devem ser considerados, incluindo a mudança de técnicas e agentes utilizados.

Diante dessa variabilidade clínica, várias propostas para classificar a HM foram apresentadas. A apresentada por Ranclev Twetman destaca-se pela forma didática; apresentando a HM em quatro formas: forma fulminante, forma frustra, espasmo de masseter e formas atípicas.

A forma frustra ou abortiva é um quadro menos óbvio; uma ou mais sinais da forma fulminante estão ausentes ou atenuados. Como os anestesistas estão mais atentos para o diagnóstico, o reconhecimento de um aumento da ETCO2 e/ou outros sinais precoces (taquicardia inexplicada, espasmo de masseter, rigidez localizada) e a retirada dos agentes halogenados pode interromper a crise.

O espasmo de masseter pode ser considerado, potencialmente, como o primeiro indicador de uma crise de HM mesmo na ausência de história familiar. Também denominado rigidez de masseter, pode ser definido como o relaxamento incompleto da musculatura da mandíbula, interferindo com a intubação, após a administração de succinilcolina, considerando o uso de uma dose adequada $\left(1-2 \mathrm{mg} \mathrm{kg}^{-1}\right)$ e a tentativa de intubação após 1 minuto. Apesar dessa definição, a avaliação de espasmo de masséter é subjetiva e, como tal, pode gerar controvérsia. 
As formas atípicas constituem-se num desafio diagnóstico e podem apresentar-se relacionadas ou não à anestesia.

Algumas das formas atípicas relacionadas à anestesia são: a) rabdomiólise perioperatória, b) início tardio do quadro com halogenado e succinilcolina, c) recorrência tardia, d) exposição ao isoflurano e succinilcolina sem reação detectável em paciente com biópsia positiva prévia, e) hipotensão como primeiro sinal de HM.

A febre pós-operatória isoladamente não é indicativa de HM, porém esta só poderá ser excluída se existirem registros adequados de $\mathrm{ETCO} 2$, freqüência cardíaca e respiratória. Informações adicionais importantes são a presença de imobilidade prolongada por alteração muscular e urina escura ou avermelhada.

Algumas das formas atípicas não relacionadas à anestesia, ou doenças correlatas, são: a) Doenças Neuromusculares (Central Core, Síndrome de King-Denborough, Miopatia de Evans), b) Síndrome Neuroléptica Maligna, c) Choque térmico/Rabdomiólise induzida por exercício, d) Síndrome HM-Símile em adolescentes do sexo masculino com Diabetes mellitus e rabdomiólise.

Como quadros suspeitos de HM, com sinais clínicos e laboratoriais sugestivos, não são posteriormente confirmados como HM, todos os pacientes que apresentarem hipercarbia inexplicada, ou rabdomiólise, perioperatória ou pós-exercício, são candidatos à biópsia muscular e teste de contratura "ín vitro", ainda o "padrão-ouro" para definição fenotípica da HM.

Por se a HM uma condição hereditária, a definição fenotípica do paciente é extremamente importante não só para ele mas também para seus familiares; a partir dessa definição podem ser realizados diagnósticos pré-sintomáticos e estudos genéticos em famílias selecionadas. Porém até o presente momento, esses estudos não podem ainda substituir o teste de contratura "ín vitro".

Apesar de requerer uma avaliação multidisciplinar, a HM é uma síndrome especificamente relacionada à anestesia e, por esta razão, deve ser de responsabilidade do anestesiologista conhecer e conduzir o diagnóstico nas diversas apresentações clínicas da mesma. 